\title{
OSTEOTOMIES OF THE CORACOID PROCESS: AN ANATOMICAL STUDY
}

Bernardo Barcellos Terra', Eduardo Antônio de Figueiredo', Carlos Stanislaw Fleury Marczyk², Gustavo Cará Monteiro', Alberto de Castro Pochini ${ }^{3}$, Carlos Vicente Andreoli ${ }^{4}$, Benno Ejnisman ${ }^{5}$

\begin{abstract}
Objective: Relate the main tendinous and ligamentous structures attached in the coracoid process, correlating it to several levels of osteotomy and describing the involved structures. Methods: Thirty shoulders were dissected. The coracoid process with mainly inserted anatomic structures was dissected, and five levels of osteotomy $(1.0 ; 1.5 ; 2.0$; $2.5 ; 3.0 \mathrm{~cm}$ ) were made from the apex of the process and the mainly involved structures were recorded. Results: In osteotomies of $1.0 \mathrm{~cm}$, in $100 \%$ of the cases only the conjoint tendon (CT). In osteotomies of $1.5 \mathrm{~cm}$ there were $63.33 \%$ of cases involved with the $\mathrm{CT}$ and the Pectoralis minor (PMi), in $20 \%$ of cases only the CT, and in $16.66 \%$ the CT, PMi, and the coracohumeral ligament (CUL). In osteotomies of
\end{abstract}

$2.0 \mathrm{~cm}$, in $80 \%$ of the shoulders, the osteotomies embraced the CT, PMi and the CUL, and in $20 \%$ only the CT and the PMi were involved. In the osteotomies of $2.5 \mathrm{~cm}$ there was involvement of the CT, PMi and CUL in $100 \%$ of cases. In the osteotomies of $3.0 \mathrm{~cm}$, six cases $(20 \%)$ have presented an injury on the trapezoid ligament, and in $100 \%$ of these osteotomies, the osteotomized distal fragment had embraced the CT, PMi, CUL. Conclusion: The knowledge of anatomic structures inserted and involved in the osteotomies cuts of the coracoid process is very importan to lead with osteotomies performed in the treatment techniques of the coracoid process. Osteotomies of $3.0 \mathrm{~cm}$ can injure the trapezoid ligament.

Keywords - Shoulder Dislocation; Joint Instability; Osteotomy

\section{INTRODUCTION}

In 1958, Helfet ${ }^{(1)}$ described a technique for correcting anterior glenohumeral instability using the coracoid process and named it the Bristow technique in homage to his mentor and professor who had taught him the technique two decades earlier. In 1954, Latarjet $^{(2)}$ had described a similar technique using screws to fix the graft to the anterior border of the glenoid. Since then, there have been many modifications and descriptions of new techniques using the coracoid process as a mechanical shutter for correcting anterior glenohumeral instability ${ }^{(3,4)}$.
The incision level for osteotomy is often not well defined, and has variously been expressed as numerical references such as $1.0 \mathrm{~cm}$ to $3.0 \mathrm{~cm}$, or anatomical reference points such as the posterior edge of the pectoralis minor tendon ${ }^{(5)}$. It is known that important anatomical structures are inserted into the coracoid process, such as the coracoclavicular ligaments, which are mainly responsible for the vertical stability of the acromioclavicular joint. Therefore, making an incision at the wrong level could injure important structures.

In this study, our aim was to study the main tendon and ligament structures that are inserted into the

1 - Physician in the Shoulder and Elbow Group of the Sports Traumatology Center, Federal University of São Paulo, São Paulo, SP, Brazil.

2 - Former Resident in the Shoulder and Elbow Group of the Sports Traumatology Center, Federal University of São Paulo, São Paulo, SP, Brazil.

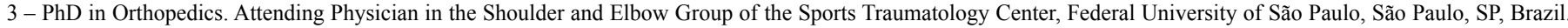

$4-\mathrm{PhD}$ in Orthopedics. Head of the Sports Traumatology Center, Federal University of São Paulo, São Paulo, SP, Brazil.

5 - PhD in Orthopedics. Head of the Shoulder and Elbow Group of the Sports Traumatology Center, Federal University of São Paulo, São Paulo, SP, Brazil.

Work performed at the Sports Traumatology Center (CETE), Department of Orthopedics and Traumatology, Federal University of São Paulo (Unifesp).

Correspondence: Rua Borges Lagoa 783, $5^{\circ}$ andar, Vila Clementino, 04038-032 São Paulo, SP. E-mail: bernardomed@hotmail.com

Work received for publication: August 5, 2011; accepted for publication: August 31, 2011.

The authors declare that there was no conflict of interest in conducting this work 
coracoid process, and to make correlations with different osteotomy levels and the structures involved in the cuts for these osteotomies, which are used in many surgical procedures within orthopedic practice, either as open or as arthroscopic procedures.

\section{MATERIAL AND METHODS}

Initially, the project for this study was approved by the Sports Traumatology Center of the Department of Orthopedics and Traumatology, Federal University of São Paulo.

Thirty shoulders from 15 fresh cadavers were dissected, of which 10 were male $(66.7 \%)$ and five were female $(33.3 \%)$, of mean age 53.9 years (range: 24 to 72 years; $s d=16.2$ years), from the death verification service. Regarding racial type, eight $(53.3 \%)$ were white and seven $(46.7 \%)$ were black.

Cadavers with scars in the shoulder region or significant limitation of passive range of motion were excluded.

The cadavers were placed in the deckchair position, and an expanded deltopectoral access was constructed (Figure 1). The clavicular and acromial insertions of the deltoid muscle were highlighted and the anatomical structures inserted in the coracoid process were isolated (Figures 2 and 3).

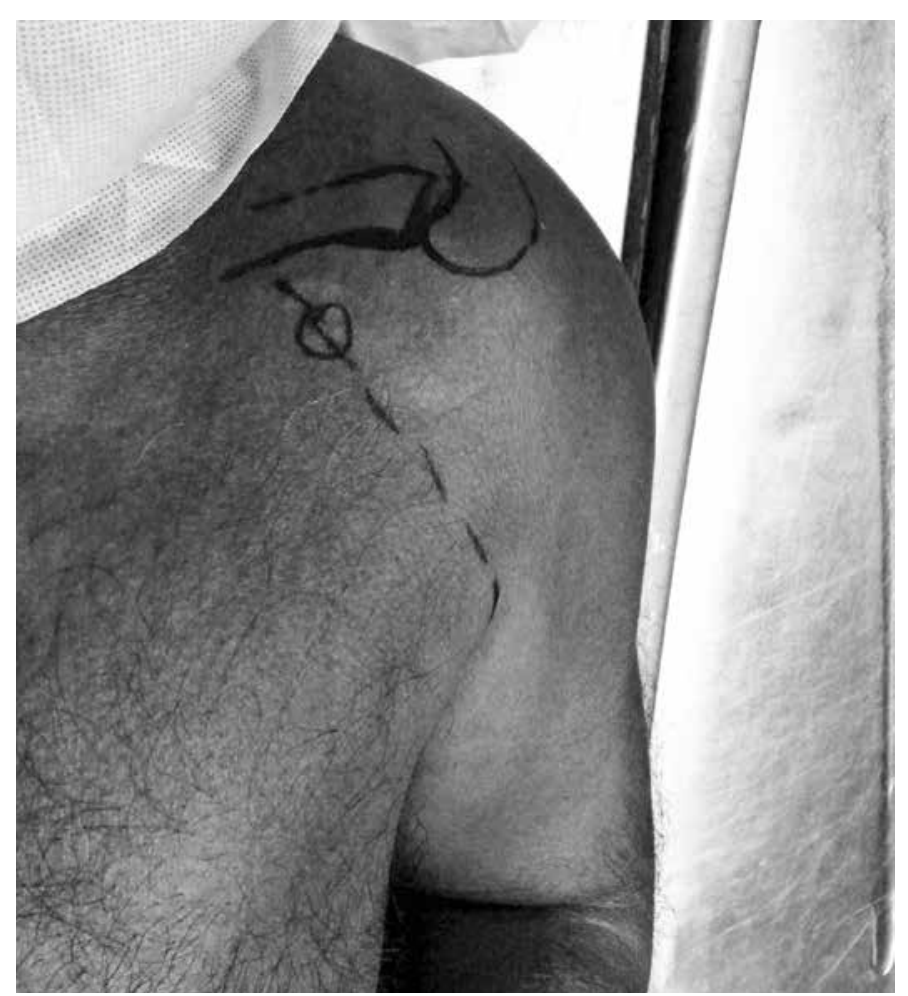

Figure 1 - Expanded deltopectoral access.

Rev Bras Ortop. 2012;47(3):337-43

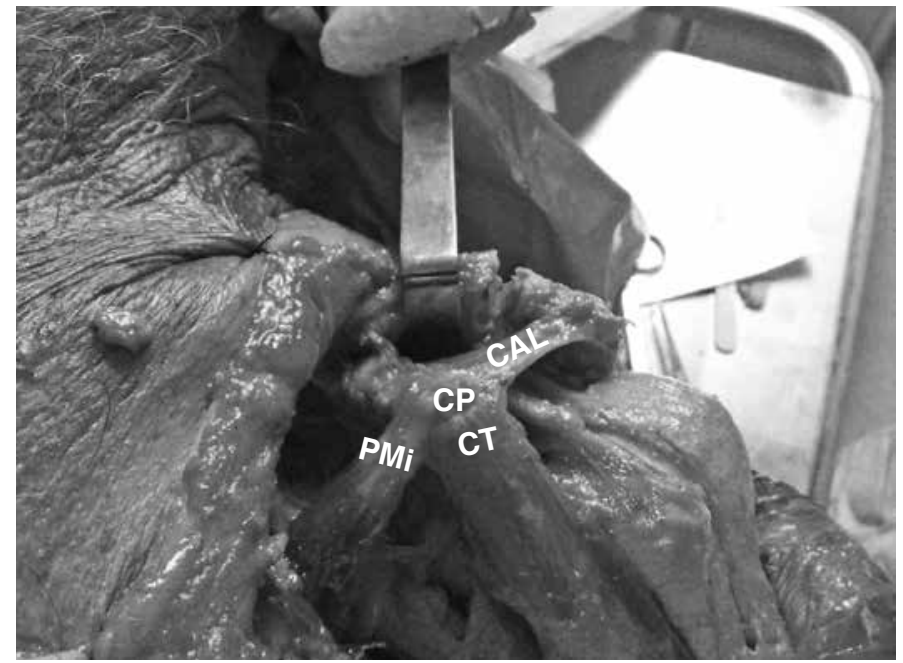

Figure 2 - Isolated coracoid process with the anatomical structures inserted. CP: coracoid process. CT: conjoined tendon. PMi: pectoralis minor. CAL: coracoacromial ligament. Left shoulder.

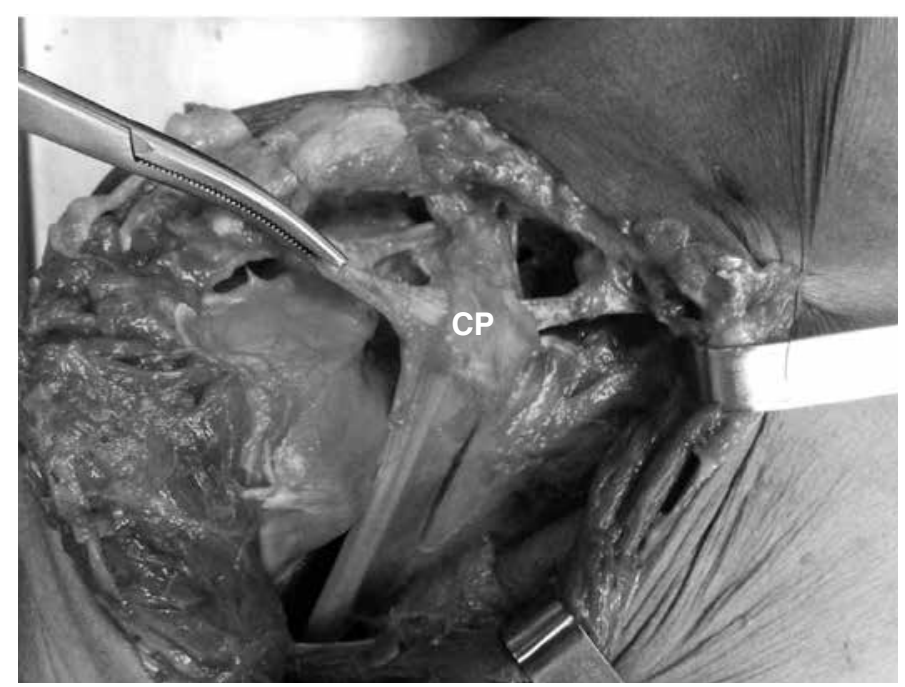

Figure 3 - Isolated coracoid process with the anatomical structures inserted. CP: coracoid process. Right shoulder.

With the aid of a non-digital calibrated pachymeter and a ruler (Figures 4 and 5), marks were made at the levels of the osteotomies, always in relation to the major axis of the coracoid process. The measurements were always made by the same two people and the mean from these measurements was used.

Following this, five levels of osteotomy were projected (Figure 6), of 1.0, 1.5, 2.0, 2.5 and $3.0 \mathrm{~cm}$ from the apex of the coracoid process, and the main ligament and tendon anatomical structures (Figures 7 and 8) inserted into the osteotomized distal fragment were defined.

\section{RESULTS}

In the osteotomies of $1.0 \mathrm{~cm}$, the conjoined tendon (CT) was involved in $100 \%$ of the cases (Figure 9). 


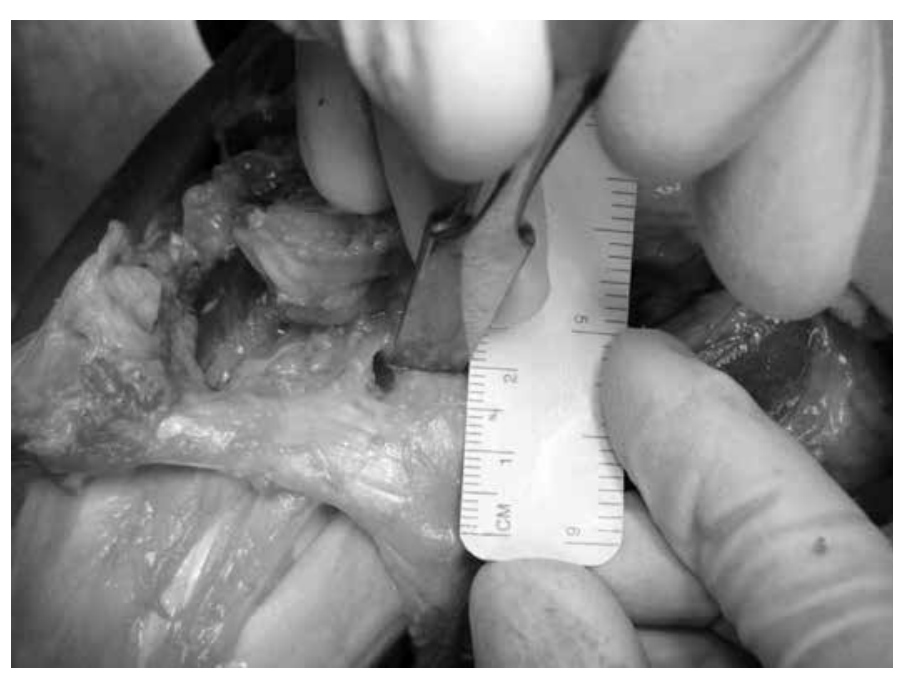

Figure 4 - Marking for osteotomy of $2.0 \mathrm{~cm}$. Right shoulder.

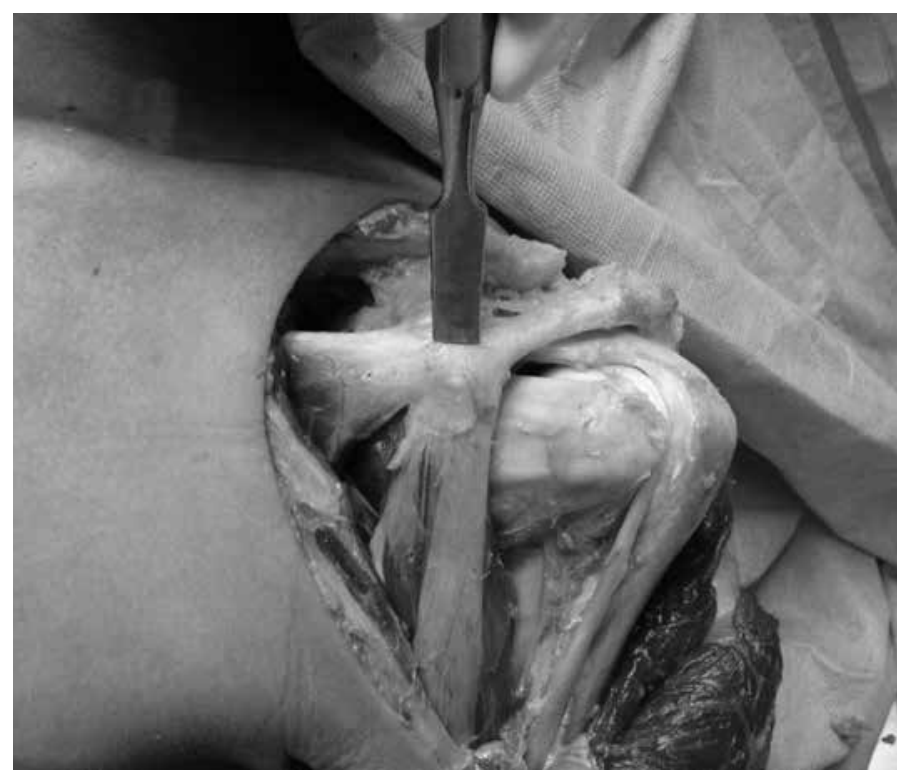

Figure 5 - Simulation of osteotomy of $1.5 \mathrm{~cm}$.

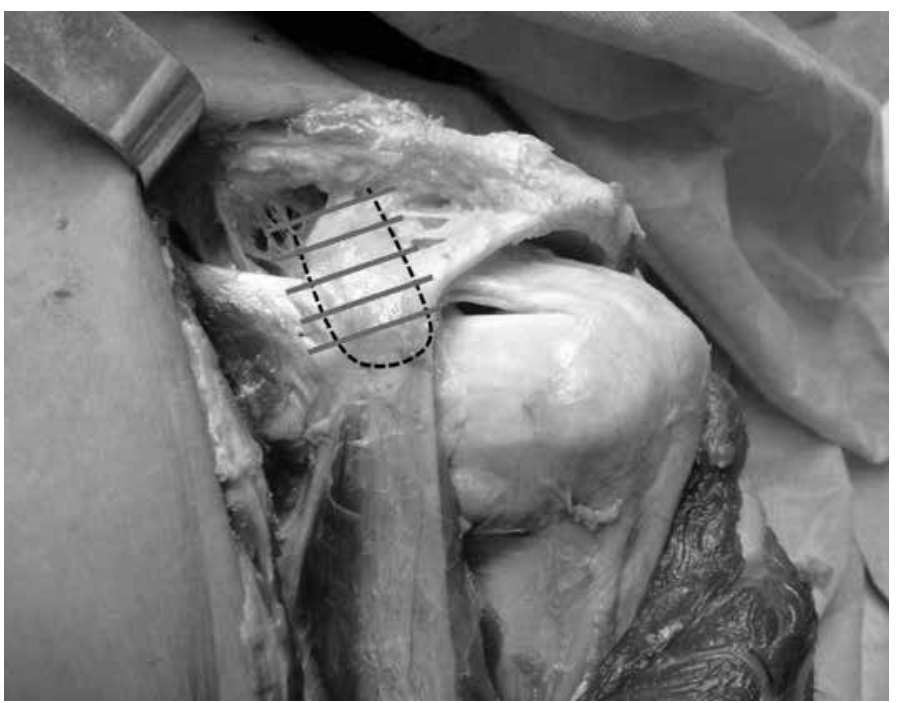

Figure 6 - Graphic representation of the five levels of osteotomies.

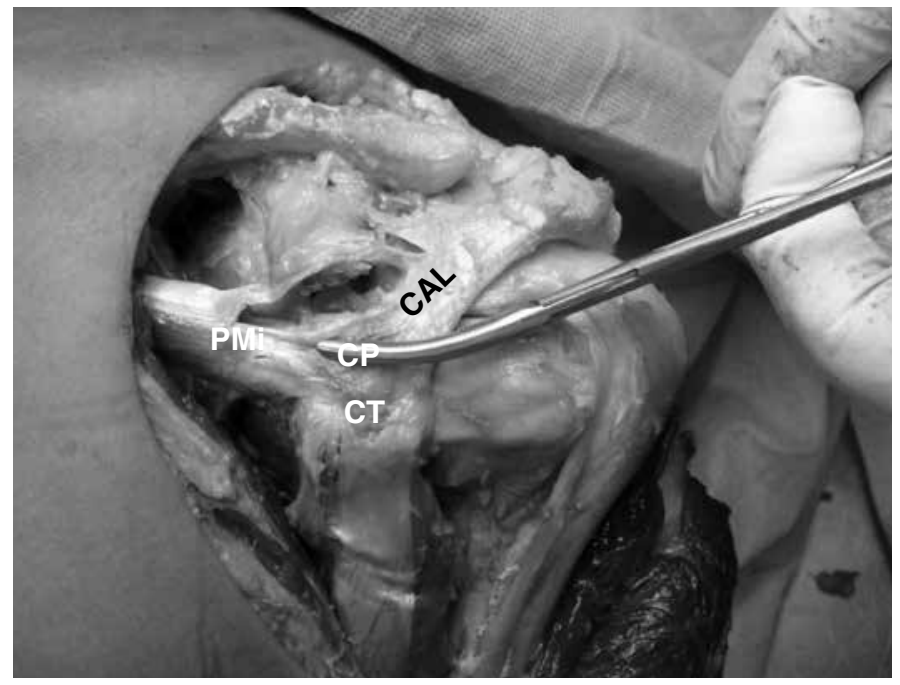

Figure 7 - Osteotomized distal fragment containing the conjoined tendon, pectoralis minor and coracoacromial ligament, after osteotomy of $2.0 \mathrm{~cm}$.

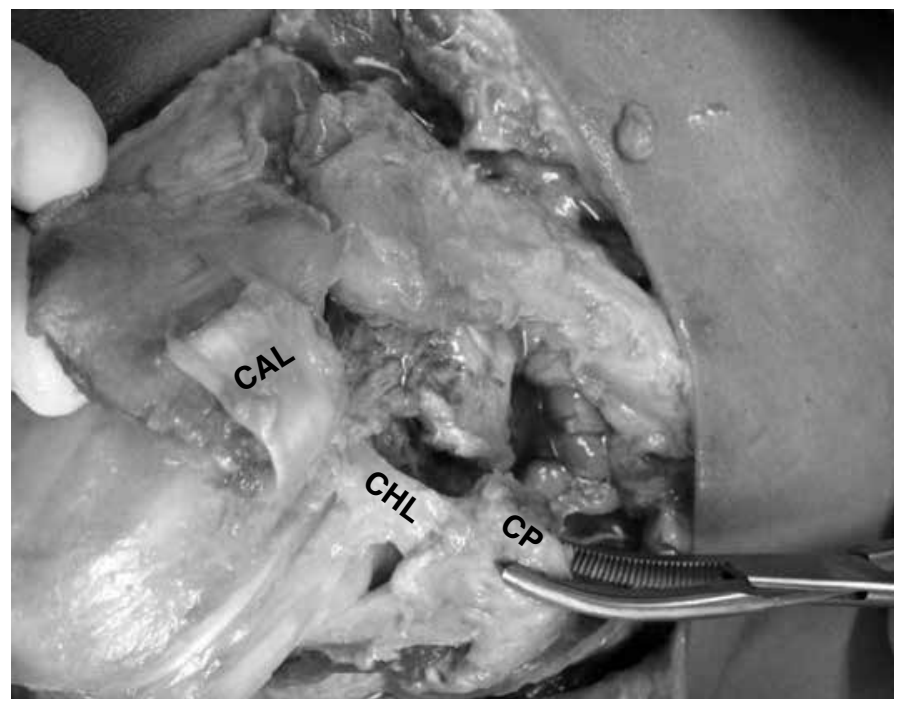

Figure 8 - Osteotomized distal fragment containing the conjoined tendon, pectoralis minor, coracoacromial ligament (which was pushed back) and coracohumeral ligament.

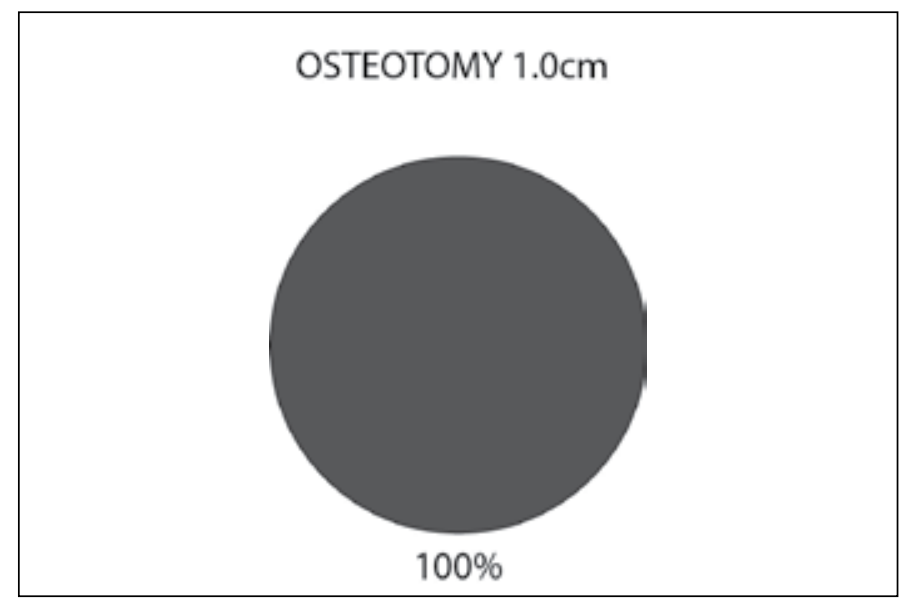

Figure 9 - Osteotomy of $1.0 \mathrm{~cm}$. In $100 \%$ of the cases, the conjoined tendon was involved. 
In the osteotomies of $1.5 \mathrm{~cm}$, the $\mathrm{CT}$ and pectoralis minor (PMi) were involved in $63.33 \%$, the $\mathrm{CT}$ alone in $20 \%$ and the CT, PMi and coracohumeral ligament (CHL) in $16.66 \%$ (Figure 10).

In the osteotomies of $2.0 \mathrm{~cm}$, the osteotomies included the CT, PMi and CHL in $80 \%$ of the shoulders. In $20 \%$, only the CT and PMi were involved (Figure 11).

In the osteotomies of $2.5 \mathrm{~cm}$, the CT, PMi and CHL were involved in $100 \%$ of the cases (Figure 12).

In the osteotomies of $3.0 \mathrm{~cm}$, there were lesions of the trapezoid ligament in six cases (20\%). In $100 \%$ of these osteotomies, the distal osteotomized fragment included the CT, PMi and CHL, and in 90\%, it also totally involved the coracoacromial ligament (Figure 13).

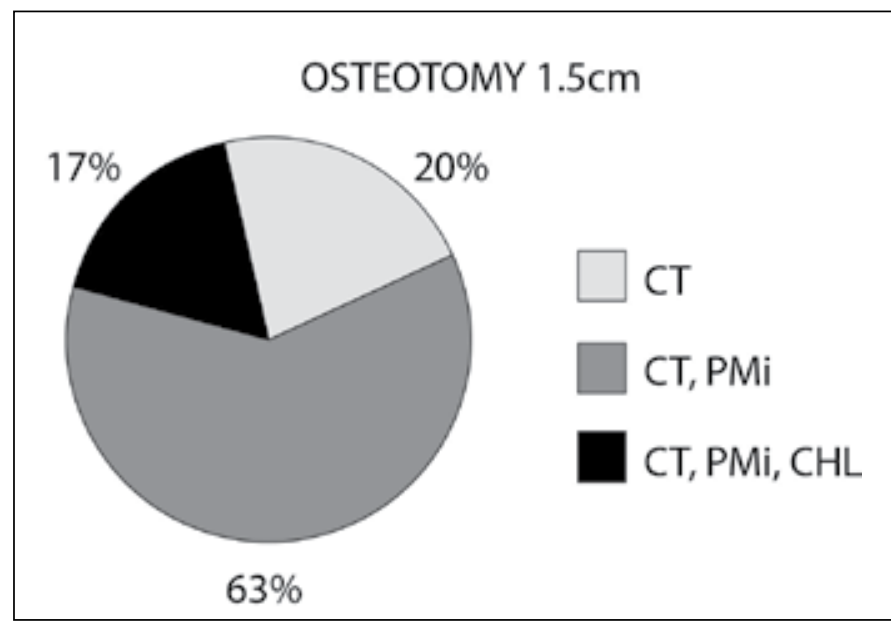

Figure 10 - Osteotomy of $1.5 \mathrm{~cm}$. CT: conjoined tendon. PMi: Pectoralis minor. $\mathrm{CHL}$ : coracohumeral ligament.

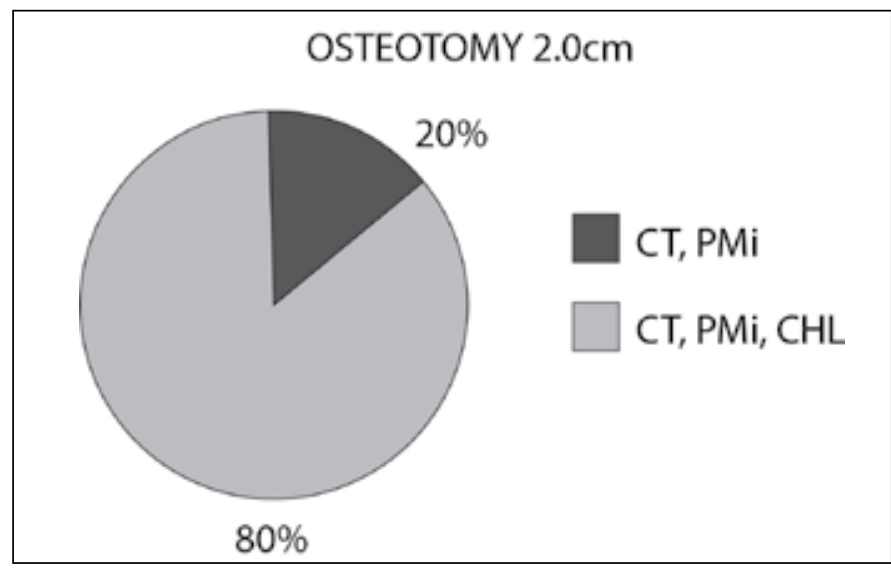

Figure 11 - Osteotomy of $2.0 \mathrm{~cm}$. CT: conjoined tendon. PMi: Pectoralis minor. $\mathrm{CHL}$ : coracohumeral ligament.

Albeit partially, the coracoacromial arch and the conjoined tendon were included in all of the osteotomy levels. The tendon of the pectoralis minor muscle was involved in $80 \%$ of the osteotomies at $1.5 \mathrm{~cm}$

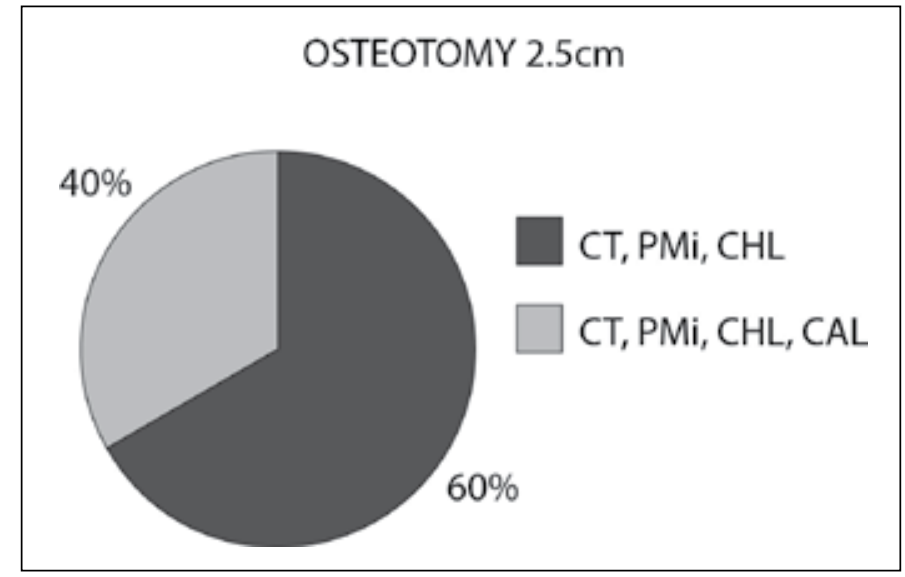

Figure 12 - Osteotomy of $2.5 \mathrm{~cm}$. CT: conjoined tendon. PMi: Pectoralis minor. CHL: coracohumeral ligament. CAL: coracoacromial ligament.

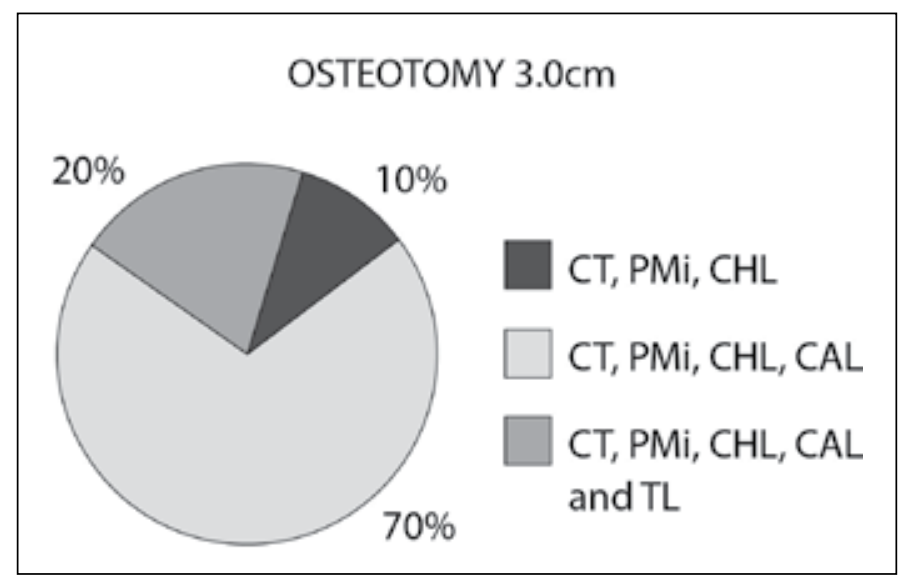

Figure 13 - Osteotomy of $3.0 \mathrm{~cm}$. CT: conjoined tendon. PMi: Pectoralis minor. $\mathrm{CHL}$ : coracohumeral ligament. CAL: coracoacromial ligament. TL: trapezoid ligament.

and the coracohumeral ligament (Figures 6 and 7) was involved in $80 \%$ of the osteotomies at $2.0 \mathrm{~cm}$.

We took the view that if an osteotomy of shorter length, for example $1 \mathrm{~cm}$, affected a given anatomical structure (such as the conjoined tendon), then the larger osteotomies $(1.5,2.0,2.5$ and $3.0 \mathrm{~cm})$ performed on the same coracoid process would also include the conjoined tendon, in addition to the other structures possibly included.

\section{DISCUSSION}

Many surgical procedures involving the coracoid process or the structures inserted in this have been described. This has mainly been in relation to treating traumatic anterior glenohumeral instability with bone loss greater than $25 \%$ of the anterior glenoid rim, lesions due to humeral avulsion of the glenohumeral ligament (HAGHL) and capsular laxity with poor-quality tissue ${ }^{(6)}$. 
However, in the literature, there are divergent references regarding the incision level of these osteotomies. Thus, there is no standardization in this regard, such that the level of these osteotomies ranges from the apex to the base of the coracoid process.

The coracoid process is a projecting bone located in the upper region of the glenoid neck, with curved morphology and directed superiorly, anteriorly and laterally. Its apex is located approximately $2.1 \mathrm{~cm}$ from the anterior glenoid rim and $1.1 \mathrm{~cm}$ from the most proximal portion of the humeral head ${ }^{(7,8)}$. This site is the origin and insertion of important tendon structures such as the tendons of the coracobrachialis muscles, short head of the biceps brachialis and the pectoralis minor, along with the coracoclavicular, coracohumeral, coracoacromial, coracocostal and glenohumeral ligaments in some cases. Its length is approximately $4.5 \mathrm{~cm}$, its width $2.5 \mathrm{~cm}$ and its thickness $1.5 \mathrm{~cm}$, depending on the region analyzed ${ }^{(9,10)}$. In our study, we did not assess its dimensions, but sought to perform osteotomies at levels cited in descriptions of surgical techniques, and to correlate these with the structures involved in the osteotomized distal fragment.

Boileau et al ${ }^{(11)}$ described the Weaver-Dunn-Chuinard procedure using a double button arthroscopically, in which the upper and lower faces of the coracoid process were used as references for positioning the guides and the endobuttons at its base. It is important to have knowledge of the structures that are inserted into the coracoid process, especially the coracoclavicular ligaments, in order to better reproduce their anatomy in cases of acromioclavicular reconstructions.

Lafosse et al ${ }^{(12,13)}$ described the Latarjet arthroscopic procedure. Within this technique, the insertion of the pectoralis minor was released and osteotomy of the coracoid process was performed posteriorly to the two guides above the coracoid process. It is important that this osteotomy should reproduce an osteotomy of around $2.5 \mathrm{~cm}$, so that no important structures are compromised. For example, the trapezoid ligament was included in the osteotomies of $3.0 \mathrm{~cm}$ in six cases.

In 1958, Helfet ${ }^{(1)}$ described the procedure popu- $^{-}$ larly known as the Bristow operation, thus named in homage to his mentor. In this, an osteotomy of $1 \mathrm{~cm}$ was performed in the coracoid process from its apex, together with insertion of the conjoined tendon, in order to correct the bone defect of the anterior glenoid rim. Subsequently, this technique was modified by several authors, such as $\mathrm{May}^{(3)}$ and Sweeney et $\mathrm{al}^{(14)}$. There are descriptions in which osteotomy anteriorly to the insertion of the tendon of the pectoralis minor is recommended.

In 1954, Latarjet $^{(2)}$ described a technique that was similar to the Bristow procedure. In this, an osteotomy was performed at the base of the coracoid process and this was fixed to the anterior glenoid rim together with the conjoined tendon, by means of a horizontal incision in the subscapularis muscle ${ }^{(15,16)}$. Patte ${ }^{(17)}$ established a the concept of triple anteroinferior stabilization, in which the bone fragment is inserted into the glenoid together with a portion of the coracoacromial ligament and the conjoined tendon, thereby providing bone, capsule-ligament and dynamic tendon-muscle stabilization $^{(4,17)}$. In this technique, the recommended osteotomy cut length is $2.5 \mathrm{~cm}$, which may involve possible anatomical variation of the insertion of the conoid ligament, as described by Terra et al ${ }^{(18)}$, who reported a distance of $1.3 \mathrm{~cm}$ from the insertion of the anatomical variation of the conoid ligament to the apex of the coracoid process.

Burkhart and De Beer ${ }^{(5)}$ described an osteotomy proximally to the angle (elbow) of the coracoid process. In three cadavers, we found lesions of the trapezoid ligament in osteotomies of $3.0 \mathrm{~cm}$. Because of this reference, the insertion may be compromised, given that the length of the coracoid process was around $4.5 \mathrm{~cm}$.

Subcoracoid impact syndrome is a less common cause of shoulder pain. The symptoms appear when there is an impact from the subscapular tendon between the coracoid process and the lesser tubercle of the humerus, which may be caused by traumatic, iatrogenic or idiopathic factors ${ }^{(19,20)}$. It is more common after a history of chronic overuse with multiple episodes of microtrauma, particularly when frontal elevation, adduction and internal rotation of the shoulder are demanded. In managing treatment for subcoracoid impact, in cases of failure of conservative treatment, coracoplasty is recommended in some cases, or an association with acromioplasty, as described by Gerber et $\mathrm{a}^{(20)}$ in 1985 . This coracoplasty may range from resection of the lateral portion of the coracoid to half of its length ${ }^{(21)}$. Therefore, it is important to have knowledge of the insertions of the anatomical structures in the coracoid process in order to avoid affecting important structures that are inserted in its lateral portion, such as the coracoacromial 
ligament, superior glenohumeral ligament and coracohumeral ligament.

The coracoclavicular ligaments are important structures for stabilizing the acromioclavicular joint, especially against superior and posterior translation, and against compressive forces. Many studies have described their footprints, both in the inferior distal third of the clavicle and in the proximal half of the coracoid process ${ }^{(9,22)}$. Harris et $\mathrm{al}^{(23)}$ described the coracoid footprint of the conoid ligament as 10.6 by $4.4 \mathrm{~mm}$ and the trapezoid ligament as 14 by $4.8 \mathrm{~mm}$. Salzmann et $\mathrm{al}^{(22)}$ described the distances from the apex of the coracoid process to the coracoid insertion of the conoid and trapezoid ligaments as 37 and $32 \mathrm{~mm}$, respectively. The insertion of the trapezoid is wider. In our study, we did not perform osteotomies larger than $3.0 \mathrm{~cm}$, but there have been descriptions of osteotomies in which the base or elbow of the process was defined as a parameter, and in such cases, these ligaments might be affected.

The tendon of the pectoralis minor muscle originates from the upper portions of the third, fourth and fifth costal arches and is inserted into the medial portion of the coracoid process. It may present anatomical variations, such that it may be inserted into the lesser tubercle, capsule, supraspinatus tendon and coracohumeral ligament ${ }^{(24,25)}$. The long-term effects of a lesion in the pectoralis minor are unknown. It is unclear whether this might give rise to alterations of scapulothoracic movements. A shortened pectoralis minor may lead to diminished posterior tilt and increased internal rotation of the scapula, thereby contributing towards possible internal impact and shoulder pain $^{(26)}$. In our study, 80 and $100 \%$ of the osteotomies of 1.5 and $2.0 \mathrm{~cm}$ respectively involved the insertion of the pectoralis minor.

The coracohumeral ligament is a thick and resistant trapezoidal structure that connects the dorsolateral portion of the proximal third of the coracoid process to the humeral head. It is located in the space of the rotators and participates in the stability of the tendon of the long head of the biceps. It is one of the main restrictors of lateral rotation of the humerus, particularly when the shoulder is adducted, and it may be thickened in situations of adhesive capsulitis. Some authors have recommended that it should be resected as part of the surgical treatment for this entity ${ }^{(27)}$.
In the present study, $80 \%$ of the cases of osteotomies of $2.0 \mathrm{~cm}$ involved the coracohumeral ligament, which may contribute towards the appearance of a SLAP lesion, as emphasized by Lee et $\mathrm{al}^{(25)}$.

One of the shortcomings of our study was that it was conducted on cadavers for which the past clinical histories relating to pathological conditions of the shoulder were unknown. It is possible that shoulders with subcoracoid impact syndrome might present alterations to the morphology of the coracoid process. Another limitation of this study was the way in which the measurements were made, since identifying the most anterior portion of the coracoid process, i.e. its apex, is a somewhat subjective measurement, given that the shape of the coracoid process is broad, expansive and curved. Furthermore, only two observers were involved in data gathering. However, our findings are relevant with regard to knowledge of the structures inserted in the coracoid process in situations when osteotomy or even coracoplasty is performed. They may serve as a reference point for future studies on this topic, especially in relation to the possible clinical morbidities and therapeutic outcomes from osteotomies affecting the insertion of these structures in the coracoid process.

There is a need for randomized prospective studies to evaluate or compare the results from these different levels of osteotomy, with the possible complications, morbidities and clinical implications that might occur in situations of deinsertion of the pectoralis minor, coracohumeral ligament, trapezoid ligament and, possibly, some cases of the superior glenohumeral ligament.

\section{CONCLUSION}

In this study, we evaluated different levels of osteotomy of the coracoid process and the structures inserted in the osteotomized fragment. Knowledge of the anatomical structures, and of their distances in relation to the apex of the coracoid process, is fundamentally important in managing the osteotomies that are performed within treatment techniques that use the coracoid process as a graft or anatomical reference. In our study, the osteotomy that compromised fewest anatomical structures was the one of $1.0 \mathrm{~cm}$, while in six cases $(20 \%)$, the trapezoid ligament was affected in the osteotomies of $3.0 \mathrm{~cm}$. 


\section{REFERENCES}

1. Helfet AJ. Coracoid transplantation for recurring dislocation of the shoulder. $\mathrm{J}$ Bone Joint Surg Br. 1958;40(2):198-202.

2. Latarjet M. [Treatment of recurrent dislocation of the shoulder]. Lyon Chir. 1954;49(8):994-7.

3. May VR, Jr. A modified Bristow operation for anterior recurrent dislocation of the shoulder. J Bone Joint Surg Am. 1970;52(5):1010-6.

4. Godinho GG, Monteiro PCVF. Tratamento cirúrgico da instabilidade anterior do ombro pela técnica de Didier-Patte. Rev Bras Ortop. 1993;28(9):640-4

5. Burkhart SS, De Beer JF. Traumatic glenohumeral bone defects and their relationship to failure of arthroscopic Bankart repairs: significance of the inverted-pear glenoid and the humeral engaging Hill-Sachs lesion. Arthroscopy. 2000;16(7):677-94

6. Doneux SP, Myiazaki AN, Lemos PEG, Souza AS, Checchia SL. Tratamento da luxação recidivante anterior do ombro: uso de enxerto ósseo na deficiência da glenóide. Rev Bras Ortop. 1997;32(9):675-82.

7. Carofino BC, Mazzocca AD. The anatomic coracoclavicular ligament reconstruction: surgical technique and indications. J Shoulder Elbow Surg. 2010;19(Suppl 2):37-46.

8. Harris RI, Vu DH, Sonnabend DH, Goldberg JA, Walsh WR. Anatomic variance of the coracoclavicular ligaments. J Shoulder Elbow Surg. 2001;10(6):585-8.

9. Rios CG, Arciero RA, Mazzocca AD. Anatomy of the clavicle and coracoid process for reconstruction of the coracoclavicular ligaments. Am J Sports Med. 2007;35(5):811-7.

10. Mazzocca AD, Spang JT, Rodriguez RR, Rios CG, Shea KP, Romeo AA, et al. 3mechanical and radiographic analysis of partial coracoclavicular ligament injuries. Am J Sports Med. 2008;36(7):1397-402.

11. Boileau P, Old J, Gastaud O, Brassart N, Roussanne Y. All-arthroscopic Weaver-Dunn-Chuinard procedure with double-button fixation for chronic acromioclavicular joint dislocation. Arthroscopy. 2010;26(2):149-60.

12. Lafosse L, Boyle S, Gutierrez-Aramberri M, Shah A, Meller R. Arthroscopic latarjet procedure. Orthop Clin North Am. 2010;41(3):393-405.

13. Lafosse L, Lejeune E, Bouchard A, Kakuda C, Gobezie R, Kochhar T. The arthroscopic Latarjet procedure for the treatment of anterior shoulder instability. Arthroscopy. 2007;23(11):1242 e1-5.

14. Sweeney HL, Mead NC, Dawson WJ, Fitzsimons P. Fourteen years experience with the modified Bristow procedure for recurrent anterior dislocations of the shoulder. Read at the annual meeting of the American Academy of Orthopedic Surgery, San Francisco, 1975.

15. Latarjet M. [Technic of coracoid preglenoid arthroereisis in the treatment of recurrent dislocation of the shoulder]. Lyon Chir. 1958;54(4):604-7.

16. Ferreira Filho AA. Tratamento da luxação anterior recidivante do ombro pela técnica de Bristow Latarjet [tese]. São Paulo: Faculdade de Medicina da Universidade de São Paulo; 1984

17. Patte D. Luxations recidivates de l'épaule. Eneyel Med Chir Techn Chirurg Orthop. 1982:44-265.

18. Terra BB, Figueiredo EA, Marczyk CS, Pochini AC, Monteiro GC, Andreoli CV, et al. Anatomical variation of the coracoclavicular ligament. Rev Bras Med. 2010;67(6):17-20.

19. Okoro T, Reddy VR, Pimpelnarkar A. Coracoid impingement syndrome: a literature review. Curr Rev Musculoskelet Med. 2009;2(1):51-5.

20. Gerber C, Terrier F, Ganz R. The role of the coracoid process in the chronic impingement syndrome. J Bone Joint Surg Br. 1985;67(5):703-8.

21. Russo R, Togo F. The subcoracoid impingement syndrome: clinical, semiologic and therapeutic considerations. Ital J Orthop Traumatol. 1991;17(3):351-8.

22. Salzmann GM, Paul J, Sandmann GH, Imhoff AB, Schottle PB. The coracoidal insertion of the coracoclavicular ligaments: an anatomic study. Am J Sports Med. 2008;36(12):2392-7.

23. Harris RI, Wallace AL, Harper GD, Goldberg JA, Sonnabend DH, Walsh WR. Structural properties of the intact and the reconstructed coracoclavicular ligament complex. Am J Sports Med. 2000;28(1):103-8.

24. Yoffey JM. The Insertion of the Pectoralis Minor Muscle. J Anat. 1927;61(Pt 3):385.

25. Lee SJ, Ha DH, Lee SM. Unusual variation of the rotator interval: insertional abnormality of the pectoralis minor tendon and absence of the coracohumeral ligament. Skeletal Radiol. 2010;39(12):1205-9.

26. Kalra K, Neri B. Isolated pectoralis minor tendon tear in a professional ice hockey player--radiographic findings and presentation. Skeletal Radiol. 2010;39(12):1251-3.

27. Manske RC, Prohaska D. Diagnosis and management of adhesive capsulitis. Curr Rev Musculoskelet Med. 2008;1(3-4):180-9. 